\title{
Epidemiological trends in nosocomial candidemia in intensive care
} Matteo Bassetti*1, Elda Righi1 ${ }^{2}$ Alessandro Costa ${ }^{2}$, Roberta Fasce ${ }^{2}$,

\author{
Maria Pia Molinari ${ }^{2}$, Raffaella Rosso ${ }^{1}$, Franco Bobbio Pallavicini ${ }^{2}$ and \\ Claudio Viscoli ${ }^{1}$
}

\begin{abstract}
Address: ${ }^{1}$ Infectious Diseases Department, S. Martino Hospital and University of Genoa, Genoa, Italy and ${ }^{2}$ Intensive Care Unit, S. Martino Hospital, Genoa, Italy

Email: Matteo Bassetti* -mattba@tin.it; Elda Righi - mattba@tin.it; Alessandro Costa - mattba@tin.it; Roberta Fasce - mattba@tin.it; Maria Pia Molinari - mattba@tin.it; Raffaella Rosso - mattba@tin.it; Franco Bobbio Pallavicini - mattba@tin.it; Claudio Viscoli - mattba@tin.it

* Corresponding author
\end{abstract}

Published: 10 February 2006

BMC Infectious Diseases 2006, 6:2I doi:10.1 186/147|-2334-6-2I

This article is available from: http://www.biomedcentral.com/|47/-2334/6/2I

(c) 2006 Bassetti et al; licensee BioMed Central Ltd.

This is an Open Access article distributed under the terms of the Creative Commons Attribution License (http://creativecommons.org/licenses/by/2.0), which permits unrestricted use, distribution, and reproduction in any medium, provided the original work is properly cited.
Received: 04 October 2005

Accepted: 10 February 2006

\begin{abstract}
Background: Infection represents a frequent complication among patients in Intensive Care Units (ICUs) and mortality is high. In particular, the incidence of fungal infections, especially due to Candida spp., has been increasing during the last years.

Methods: In a retrospective study we studied the etiology of candidemia in critically ill patients over a five-year period (1999-2003) in the ICU of the San Martino University Hospital in Genoa, Italy.

Results: In total, 182 episodes of candidaemia were identified, with an average incidence of 2.22 episodes/10 000 patient-days/year (range 1.25-3.06 episodes). Incidence of candidemia increased during the study period from I.25 in 1999 to 3.06/I0 000 patient-days/year in 2003 . Overall, $40 \%$ of the fungemia episodes (74/I82) were due to C.albicans, followed by C. parapsilosis(23\%), C.glabrata (15\%), C.tropicalis (9\%) and other species (13\%). Candidemia due to non-albicans species increased and this was apparently correlated with an increasing use of azoles for prophylaxis or empirical treatment.
\end{abstract}

Conclusion: The study demonstrates a shift in the species of Candida causing fungemia in a medical and surgical ICU population during a 5 year period. The knowledge of the local epidemiological trends in Candida species isolated in blood cultures is important to guide therapeutic choices.

\section{Background}

Candida is an increasing cause of bloodstream infection (BSI), causing significant mortality and morbidity, especially in non-neutropenic critically ill patients. Its overall incidence raised fivefold in the past ten years and Candida $s p p$. is currently between the fourth and the sixth most common nosocomial bloodstream isolate in American and European studies [1,2]. Despite the availability of effective antifungal therapy, mortality in the last decade remained high, ranging from $36 \%$ to $63 \%$ [3]. In terms of species of Candida, recently, a shift towards non-albicans species was reported by some authors especially in hematological and transplanted patients [4-7]. Some of these emerging species has been correlated with increased viru- 
lence [8], and sometimes, but not always, with increased mortality [9]. An increasing role for non-albicans species was also noticed in studies performed among ICU patients, although the issue is somewhat controversial [3,10-12].

As shown by the SENTRY antimicrobial surveillance program [1], C. albicans is still the species most frequently isolated in BSI $[13,14]$, while in other groups of patients nonalbicans species have surpassed C.albicans as a cause of candidemia. C.parapsilosis and C.tropicalis are isolated more frequently than C.albicans in some European and Latin American centres [15].

A reduced antifungal susceptibility in non-albicans species and a correlation with routine fluconazole prophylactic use has been suggested $[5,16]$. Intrinsic and emerging resistance of non-albicans species to azoles actually represents a major challenge for empirical therapeutic and prophylactic strategies [17].

We have performed a retrospective study of Candida spp. BSI in the ICU of the San Martino University Hospital, in Genova, Italy, between 1999 and 2003, with the double aim of understanding if any change was detectable in the distribution of the various Candida species as cause of BSI over the years and of estimating whether this change, if existing, was correlated with the use of fluconazole for prophylaxis or therapy.

\section{Methods}

The ICU of the San Martino General Hospital in Genova, Italy, is a mid-size medical and surgical unit with 18 beds and about 500 admissions per year. Patients who devel- oped a clinically and microbiologically documented candidemia were identified through a microbiological laboratory survey and data were recorded in an electronic data base. The patients chart review was performed in order to identify clinically relevant episodes. Candidemia was defined as at least one positive blood culture yielding Candida spp. in a patients with fever or other clinical signs of infection. Nosocomial candidemia was defined as a candidemia occurring at least $48 \mathrm{~h}$ after admission. During the study period there were no changes in microbiological laboratory techniques. Candida species were isolated from blood using BACTEC 860 system (Becton Dickinson, INC, Sparks, MD). The species were identified using API-32C system (bioMerieux Vitek, Inc, St. Louis, MI). Frequencies and descriptives of demographic and clinical characteristics of the patient population were determined.

All patients were evaluable for the inclusion in this study. The Chi-square-test or the Fisher Exact-test were used to compare categorical variables. Chi-square-test for trend was used to estimate the relationship between albicans and non-albicans isolation rates during the years of study. In order to understand whether or not there was a correlation between the distribution of the different Candida species causing BSI and the use of fluconazole, the DDD of fluconazole per 1000 patient-days was calculated and plotted against the type of isolated Candida on a yearly basis. A logistic regression analysis between C. albicans rate and fluconazole usage was then performed.P values < 0.05 were considered significant.

All the patients consented to participation in the study and publication of the results.

Table I: Patient characteristics of 182 patients with candidemia.

\begin{tabular}{|c|c|c|c|}
\hline Characteristics & C.albicans $(n=74)$ & C. non albicans $(n=108)$ & $P$ value \\
\hline Male & 41 & 70 & NS \\
\hline Famale & 33 & 38 & NS \\
\hline Age (years) mean \pm SD Range & $58.4 \pm 15.4$ & $64.4 \pm 11.4$ & $<0.05$ \\
\hline Central venous catheterization & $65 / 74$ & $99 / 108$ & NS \\
\hline Parenteral nutrition & $38 / 74$ & $64 / 108$ & NS \\
\hline Ventilator dependence mean \pm SD Range & $27.9 \pm 23.6$ & $32.6 \pm 24.5$ & NS \\
\hline Apache II score mean \pm SD Range & $21.8 \pm 7.4$ & $25.6 \pm 9.8$ & NS \\
\hline \multicolumn{4}{|l|}{ Underline disease } \\
\hline Surgery & $33 / 74$ & $40 / 108$ & NS \\
\hline Solid tumor & $11 / 74$ & $35 / 108$ & $<0.05$ \\
\hline Solid organ transplant & $8 / 74$ & $10 / 108$ & NS \\
\hline Trauma & $7 / 74$ & $9 / 108$ & NS \\
\hline Hematological malignancies & $6 / 74$ & $10 / 108$ & NS \\
\hline Burn & $4 / 74$ & $3 / 108$ & NS \\
\hline Others & $5 / 74$ & $1 / 108$ & NS \\
\hline
\end{tabular}

NS = Not significant 


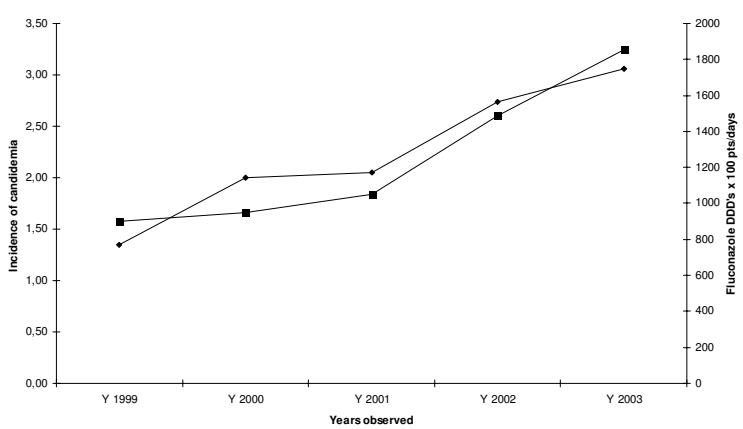

Figure I

$\diamond$ incidence of candidemia episodes/ 10000 patient-days/year; DDD's of fluconazole $\times 100$ pts/days.

\section{Results}

In total, 182 episodes of candidaemia were identified, with an average incidence of 2.22 episodes/10 000 patient-days/year (range 1.25-3.06 episodes), as shown in table 1 . Incidence of candidemia increased during the study period from 1.25 in 1999 to 3.06 episodes/10 000 patient-days/year in 2003 (Figure 1). The demographic and clinical characteristics of the patients are summarized in table 1. Patients with Candida non-albicans fungemia were significantly older. There were no significant differences in sex, age, central venous, catheterization, parenteral nutrition, ventilator dependence, Apache II score and other underline disease. Non-albicans candidemia are significantly more frequent in patients with solid tumor. Overall, $40 \%$ of the episodes (74/182) were due to C.albicans, followed by C. parapsilosis(23\%), C.glabrata (15\%), C.tropicalis (9\%) and other species (13\%) (Table 2) The percentage of C. albicans which was isolated in about $60 \%$ of the episodes in the first years of study, progressively dropped to $24 \%$, with a median percentage year reduction of $13 \%$, while the absolute number and the incidence of C.albicans did not vary during the years observed. The change was statistically significant $\left(\mathrm{K}^{2}=\right.$ 24.452; $\mathrm{p}<0.0001$ ), although in absence of a rigorous linear trend. Non-albicans strains steadily increased throughout the study period surpassing C.albicans in the second half of the study and raising from $21 \%$ to $67 \%(\mathrm{P}=0.01)$ (Figure 2). The proportion of non-albicans species went from $38 \%$ and $21 \%$ of total isolates in the years $1999-$ 2000 and then to $67 \%, 73 \%$ and 76\% in 2001, 2002 and 2003, respectively. Among non-albicans strains, in 2002 we noted an increase of C.parapsilosis isolation rates, which reached $51 \%$ of total, while absence of C.tropicalis was noted in the years 2000-2001.

The use of fluconazole for prophylaxis or therapy increased four times during the study period. Logistic regression analysis showed a statistically significant correlation between the shift from albicans to non-albicans strains and the yearly fluconazole consumption. As shown in figure 3, an increase of 100 fluconazole DDDs corresponded to a reduction in the isolation of $\mathrm{C}$. albicans of $5 \%$.

\section{Discussion}

Our study demonstrates a shift in the species of Candida causing fungemia in a medical and surgical ICU population during a 5 year period. The proportion due to C. albicans decreased whereas that due to other species, such as C. parapsilosis, C. tropicalis and C.glabrata, increased. Such an increase in non-albicans species was also seen in retrospective reviews of candidemias $[4,10,12,15,16]$. In contrast to hematologic patients where a decrease in C.albicans infection resulted in a significant reduction in the incidence of candidemia [17], in our experience the overall incidence actually increased (Table 1; Figure 1). Traditionally, C.tropicalis has been the second and C.glabrata the third or fourth most common Candida species recovered from blood $[4,8]$. In our study C.parapsilosis sur-

Table 2: Incidence and distribution of candidemia in the years 1999- 2003 in S. Martino Hospital ICU expressed in number and percentage of isolates. Polymicrobial infections were excluded.

\begin{tabular}{|c|c|c|c|c|c|c|}
\hline & 1999 & 2000 & 2001 & 2002 & 2003 & Total \\
\hline & \multicolumn{6}{|c|}{ Number of isolates (percentage of species in the year) } \\
\hline C.albicans & $13(62)$ & $26(79)$ & II (33) & $12(27)$ & $12(24)$ & $74(40)$ \\
\hline C.parapsilosis & $2(9)$ & 0 & $4(12)$ & $23(5 I)$ & $13(26)$ & $42(23)$ \\
\hline C. glabrata & 0 & I (3) & $12(36)$ & $2(4)$ & $12(24)$ & $27(15)$ \\
\hline C. tropicalis & $5(24)$ & 0 & 0 & $7(16)$ & $5(10)$ & $17(9)$ \\
\hline Othres (C.kruzei, C.guillermondii, C.Iusitanae) & $\mathrm{I}(5)$ & $6(18)$ & $6(19)$ & $\mathrm{I}(2)$ & $8(16)$ & $24(13)$ \\
\hline Total candidemia & 21 & 33 & 33 & 45 & 50 & 182 \\
\hline Incidence of candidemia/I 0000 patient-days/year & 1.25 & 2 & 2.05 & 2.74 & 3.06 & 2.22 \\
\hline Incidence of candidemia due to $C$.albicans/ $/ 0000$ patient-days/year & 0.84 & 1.58 & 0.66 & 0.73 & 0.73 & 0.91 \\
\hline
\end{tabular}




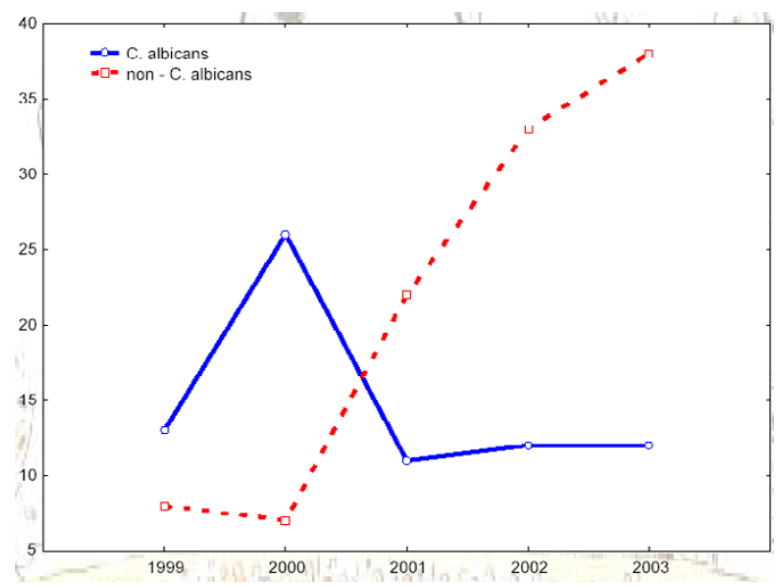

Figure 2

Line plot representation of Candida albicans and Candida nonalbicans isolates rates during the study period.

passed the other non-albicans to become the most common species isolated after C.albicans. The high incidence of C.parapsilosis candidemia has been previously reported in South American hospitals [15,18,19]. The role of C.parapsilosis as an exogenous acquired pathogen is well known and has been associated with parenteral alimentation and intravascular devices [20], commonly used in critical patients.

Several investigators postulated that the widespread use of fluconazole would have selected yeast species intrinsically resistant or less sensitive to fluconazole, such as Candida kruzei, C. glabrata or C. tropicalis [21-23]. Some published reports confirmed this hypothesis, while others did not $[2,24,25]$. At the San Martino Hospital, the incidence of infections caused by most non-albicans Candida species changed substantially during the study period. These changes occurred in concomitance with a four fold increase in the use of fluconazole. In our ICU, during 2001 and the following years, the usage of fluconazole at dosage of 200-400 mg/day increased because of the changing in prophylactic strategy in high-risk patients, according to the efficacy demonstrated in various reports $[26,27]$. A logistic regression analysis showed a statistically significant correlation between the shift from albicans to non-albicans strains and the yearly fluconazole consumption, as shown in figure 2 . However, it be recognised that other events might have played a role in the selection of different species. For example, in the last 2 years of the study, the increased proportion of candidemias due to C.parapsilosis, a yeast species almost always susceptible to fluconazole, is not readily explained by increased fluconazole use. It is likely that changes in the

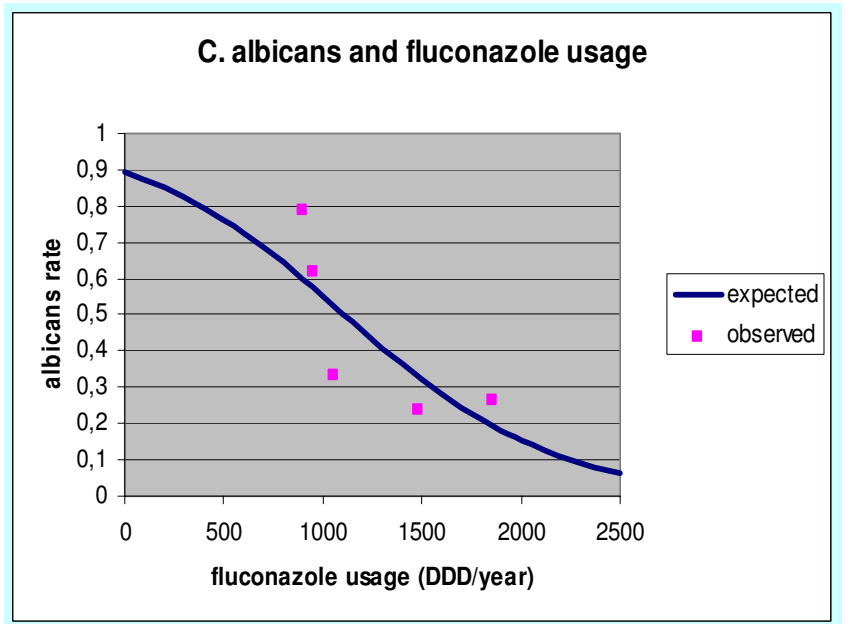

\section{Figure 3}

Correlation using logistic regression between percentage reduction of $C$. albicans isolation rates and fluconazole use [DDDs per year].

proportion of fungemias due to C. parapsilosis reflect nosocomial acquisition of this species.

In ICU, the role for the use of fluconazole remains controversial, since fluconazole was demonstrated to reduce the incidence of Candida infections in a particular group of high-risk patient population [26-28].

Though limited by its retrospective nature, our study focuses the attention on predominance of non-C.albicans isolates, usually less susceptible or intrinsically resistant to fluconazole.

It is well known that positive blood culture for Candida $s p p$. is a life threatening situation, requiring an empirical antifungal treatment which should started with the appropriate agents as soon as possible. Therefore the knowledge of the local epidemiological trends in Candida species isolated in blood cultures is important to guide therapeutic choices.

The data we have reported are based on records from the microbiology laboratory, and thus, have certain inherent limitations. Our study did not address specific risk factors, which undoubtedly play a role in the selection of species causing fungemia. However, this type of study does reveal overall long-term trends that should be helpful to physicians and antibiotic use committees in establishing guidelines for the appropriate use of antifungal agents.

\section{Competing interests}

The author(s) declare that they have no competing interests. 


\section{Authors' contributions}

MB: Data acquisition, data/statistical analyses, drafting the manuscript

ER: Sample collection, drafting the manuscript, critically revising for medical content

AC: Sample collection, critically revising for medical content

RF: Sample collection, critically revising for medical content

MPM: Data acquisition, data analyses

RR: Study design and conception, critically revising for medical content

FBP: Study design, conception and coordination

CV: Study design, conception and coordination

All authors contributed to writing of the final manuscript.

All authors read and approved the final manuscript

\section{Acknowledgements}

The study was conducted independently of the funding agencies and pharmaceutical companies.

We are grateful to Dr. Mario Cruciani and Prof. Carlo Mengoli for his helpful contribution in statistical analyses.

\section{References}

I. Pfaller MA, Diekema DJ, Jones RN, Sader HS, Fluit AC, Hollis RJ, Messer SA, SENTRY Participant Group: International surveillance of bloodstream infections due to Candida species: frequency of occurrence and in vitro susceptibilities to fluconazole, ravuconazole, and voriconazole of isolates collected from 1997 through 1999 in the SENTRY antimicrobial surveillance program. I Clin Microbiol 200 I, 39:3254-9.

2. Marchetti O, Bille J, Fluckiger U, Eggimann P, Ruef C, Garbino J, Calandra T, Glauser MP, Tauber MG, Pittet D: Fungal Infection Network of Switzerland. Epidemiology of candidaemia in Swiss tertiary care Hospitals: secular trends 1991-2000. Clin Infect Dis 2004, 38:311-20.

3. Vos A, Noble JL, Verduyn-Lunel FM, Foudraine NA, Meis JF: Candidemia in ICU patients: risk factors for mortality. Infect 1997, 25:10-13.

4. Nguyen MH, Peacock JE, Morns AJ, Tanner DC, Nguyen ML, Snydman DR, Wagener MM, Rinaldi MG, Yu VL: The changing face of Candidemia: emergence of non-Candida albicans species and antifungal resistance. Am J Med 1996, 100:617-623.

5. Rocco TR, Reinsert SE, Simms HH: Effects of fluconazole administration in critically ill patients: analysis of bacterial and fungal resistance. Arch Surg 2000, 135:160-65.

6. Pfaller MA, Jones RN, Doern GV, Sader HS, Messer SA, Houston A, Coffman S, Hollis RJ: Bloodstream infections due to Candida species: SENTRY antimicrobial surveillance program in North America and Latin America, 1997-1998. Antimicrob Ag Chemother 2000, 44:747-5I.

7. Shelenz S, Grandsen WR: Candidemia in a London teaching Hospital: analysis of $\mathbf{2 8}$ cases over a 7 years period. Mycoses 2003, 46:390-6.
8. Kornshian SV, Uwaydah AK, Sobel JD, Crane LR: Fungemia caused by Candida species and Torulopsis glabrata in the hospitalized patient: frequency, characteristics and evaluation of factors influencing outcome. Rev Infect Dis 1989, I I:379-390.

9. Blot S, Vandewoude K, Hoste E, Poelaert J, Colardyn F: Outcome in critically ill patients with candidal fungaemia: Candida albicans vs. Candida glabrata. J Hosp Infect 200I, 47:308-I3.

10. Hope W, Morton A, Eisen DP: Increase in prevalence of nosocomial non-Candida albicans candidaemia and the association of Candida krusei with fluconazole use. J Hosp Infect 2002, 50:56-65.

II. McMullan R, McClurg R, Xu J, Moore JE, Millar BC, Crowe M, Hedderwick S: Trends in the epidemiology of Candida bloodstream infections in Northern Ireland between January 1984 and December 2000. J Infect 2002, 45:25-28.

12. Al-Jasser A, Elkhizzi NA: Distribution of Candida species among bloodstream isolates. Saudi Med J 2004, 25:566-69.

13. Yamamura D, Rotstein C, Nicolle LE, loannou S: Candidemia at selected Canadian sites: results from the fungal disease registry 1992-1994. CMAJ I999, I60:493-9.

14. Klingspor L, Tornqvist E, Johansson A, Petrini B, Forsum U, Hedin G: A prospective epidemiological survey of candidemia in Sweden. Scand J Infect Dis 2004, 36:52-55.

15. Colombo AL, Nucci M, Salomao R: High rate of non-albicans candidemia in Brazilian tertiary care hospitals. Diagn Microbiol Infect Dis 1999, 34:28I-86.

16. Luzzati R, Amalfitano G, Lazzarini L, Soldani F, Bellino S, Solbiati M, Danzi MC, Vento S, Todeschini G, Vivenza C, Concia E: Nosocomial candidemia in non-neutropenic patients at an Italian tertiary care hospital. Eur J Clin Microbiol Infect Dis 2000, I 9:602-7.

17. Safdar A, Perlin DS, Armstrong D: Hematogenous infections due to Candida parapsilosis: changing trends in fungemic patients at a comprehensive cancer center during the last four decades. Diagn Microbiol Infect Dis 2002, 44: | |-6.

18. Levin AS, Costa SF, Mussi NS, Basso M, Sinto SI, Machado C, Geiger DC, Villares MC, Schreiber AZ, Barone AA, Branchini ML: Candida parapsilosis fungemia associated with implantable and semiimplantable central venous catheters and the hands of healthcare workers. Diagn Microbiol Infect Dis 1998, 30:243-9.

19. Pfaller MA, Jones RN, Doern GV, Sader HS, Hollis RJ, Messer SA: International surveillance of bloodstream infections due to Candida species: frequency of occurrence and antifungal susceptibilities of isolates collected in 1997 in the United States, Canada, and South America for the SENTRY Program. The SENTRY Participant Group. J Clin Microbiol 1998, 36: I886-9.

20. Pfaller MA: Epidemiology of candidiasis. J Hosp Infect 1995, 30(Suppl):329-38.

21. Abi-Said D, Anaissie E, Uzun O, Raad I, Pinzcowski H, Vartivarian S: The epidemiology of hematogenous candidiasis caused by different Candida species. Clin Infect Dis 1997, 24: I I 22-8.

22. White $\mathrm{MH}$ : The contribution of fluconazole to the changing epidemiology of invasive Candida infection. Clin Infect Dis 1997, 24: I I 29-30.

23. Berrouane YF, Herwaldt LA, Pfaller MA: Trends in antifungal use and epidemiology of nosocomial yeast infections in a University Hospital. J Clin Microbiol 1999, 37:53 I-37.

24. Malani PN, Bradley SF, Little RS, Kauffman CA: Trends in species causing fungaemia in a tertiary care medical centre over 12 years. Mycoses 200I, 44:446-9.

25. Asmundsdottir LR, Erlendsdottir H, Gottfredsson M: Increasing incidence of Candidemia: results from a 20-year nationwide study in Iceland. J Clin Microbiol 2002, 40:3489-92.

26. Pelz RK, Hendrix CW, Swoboda SM, Diener-West M, Merz WG, Hammond J, Lipsett PA: Double-blind placebo-controlled trial of fluconazole to prevent candidal infections in critically ill surgical patients. Ann Surg 200I, 233:542-548.

27. Eggimann P, Francioli P, Bille J: Fluconazole prophylaxis prevents intra-abdominal candidiasis in high-risk surgical patients. Crit Care Med 1999, 27:1066-72.

28. Shorr AF, Chung K, Jackson WL, Waterman PE, Kollef MH: Fluconazole prophylaxis in critically ill surgical patients: a meta-analysis. Crit Care Med 2005, 33:1928-1935. 


\section{Pre-publication history}

The pre-publication history for this paper can be accessed here:

http://www.biomedcentral.com/1471-2334/6/21/prepub

Publish with Bio Med Central and every scientist can read your work free of charge

"BioMed Central will be the most significant development for disseminating the results of biomedical research in our lifetime. " Sir Paul Nurse, Cancer Research UK

Your research papers will be:

- available free of charge to the entire biomedical community

- peer reviewed and published immediately upon acceptance

- cited in PubMed and archived on PubMed Central

- yours - you keep the copyright 